\title{
Energy exchange processes in the marginal ice zone of the Barents Sea, Arctic Ocean, during spring 1999
}

\author{
Boris V. IVANOV, ${ }^{1}$ Sebastian GERLAND, ${ }^{2}$ Jan-Gunnar WINTHER, ${ }^{2}$ Harvey GOODWIN ${ }^{2}$ \\ ${ }^{1}$ Arctic and Antarctic Research Institute, 199397 St Petersburg, Russia \\ E-mail:b_ivanov@aari.nw.ru \\ ${ }^{2}$ Norwegian Polar Institute, The Polar Environmental Centre, N-9296 Tromsø, Norway
}

\begin{abstract}
We present some new results describing energy exchange processes of drifting sea ice in the marginal ice zone (MIZ) in the Barents Sea, Arctic Ocean. All measurements and observations of meteorological parameters and ice conditions were taken on board the Norwegian research vessel Lance from 3 to 22 May 1999. Components of surface heat balance were measured and correlated with ice conditions and synoptic observations. These results can be used in atmospheric boundary layer modelling as lower boundary conditions. A relationship was found between modelled turbulent heat fluxes and observed sea-ice concentrations.
\end{abstract}

\section{INTRODUGTION}

The main aim of this investigation was to calculate the energy exchange fluxes in the marginal ice zone (MIZ) of the Barents Sea, Arctic Ocean, during spring and verify them with observed sea-ice and meteorological conditions.

Knowledge of surface energy exchange fluxes in the MIZ is important for understanding the complex processes in the atmospheric boundary layer in the Barents Sea and similar areas in the Arctic with pack-ice and fast-ice cover. Further, this information is needed for modelling the atmospheric boundary layer in the MIZ (e.g. Overland and others, 1983; Brown, 1986).

This study was carried out during a cruise to the northwestern Barents Sea with the Norwegian research vessel Lance in spring 1999. Both standard and specialized meteorological observations and radiation measurements were collected. The study area extends from $76^{\circ}$ to $78^{\circ} \mathrm{N}$ and from the island of Hopen $\left(25^{\circ} \mathrm{E}\right)$ to the line of longitude at $35^{\circ} \mathrm{E}$ (Fig. 1). The exchange of water masses between the Barents Sea, the North Atlantic and the Arctic Ocean strongly influences the position and composition of the Barents Sea MIZ (Vinje and Kvambekk, 1991). The bathymetry also affects the MIZ.

\section{INSTRUMENTS, METHODS AND GOMPUTATIONS}

Incoming shortwave solar radiation and the balance of longwave radiation were measured continuously from 3 to 22 May 1999. Air temperature, air pressure, relative humidity (at $12 \mathrm{~m}$ a.s.l.) and wind speed and direction (at $24 \mathrm{~m}$ a.s.l.) were logged every 3 hours by the ship's meteorological station. In addition, sea-water temperature was measured. Atmospheric and sea-ice conditions were observed from the ship's bridge every 3 hours. The ice description included esti- mating the proportion of different ice types (slush, pancake ice, dark and light nilas, young ice (grey ice, grey/white ice), white first-year ice, multi-year ice, brash ice and open water), floe size (seven size classes: $<1 \mathrm{~m}, 1-3 \mathrm{~m}, 3-10 \mathrm{~m}, 10-100 \mathrm{~m}$, $100-1000 \mathrm{~m},>1 \mathrm{~km}$, vast), snow-cover thickness, percentage of ridging and rafting, and percentage of ice coloured by sediments or algae. The nomenclature for ice types follows terms according to Steffen (1986). During transects perpendicular to the ice edge or under rapidly changing ice conditions, extra observations were made. Radiation characteristics (incoming solar radiation, longwave radiation balance and surface radiation temperature) were obtained using Russian radiation sensors installed on the roof of the crow's nest, $22 \mathrm{~m}$ a.s.l. Incoming shortwave solar radiation $(300-3000 \mathrm{~nm})$ was measured using a thermoelectric pyranometer (TEP-29). The sensitivity of this sensor is $0.067 \mathrm{mV} \mathrm{W}^{-1} \mathrm{~m}^{-2}$, and its response time $10 \mathrm{~s}$. The components of longwave radiation balance (3500-17000 nm) were measured with upward- and downward-looking pyranometers and pyrgeometers. The opening angle was $90^{\circ}$ (up) and $45^{\circ}$ (down). The sensitivity of these sensors was 0.055 and $0.025 \mathrm{mV} \mathrm{W}^{-1} \mathrm{~m}^{-2}$, respectively, with a response time of $15 \mathrm{~s}$. These sensors consist of a thermopile and are shielded by a germanium hemisphere. The radiation parameters were logged every $10 \mathrm{~min}$ using a standard data logger.

To calculate turbulent heat fluxes an algorithm based on the Monin-Obukhov similarity theory was used (Monin and Obukhov, 1954; Monin and Yaglom, 1975). This theory has previously been used by for example Ivanov and Makshtas (1988) and Makshtas (1991) for measurements in the atmosphere water/ice surface layer. The main concept of this theory is that within the surface layer the relationship between time-averaged turbulent flow characteristics (wind velocity, air temperature and relative humidity) and height 


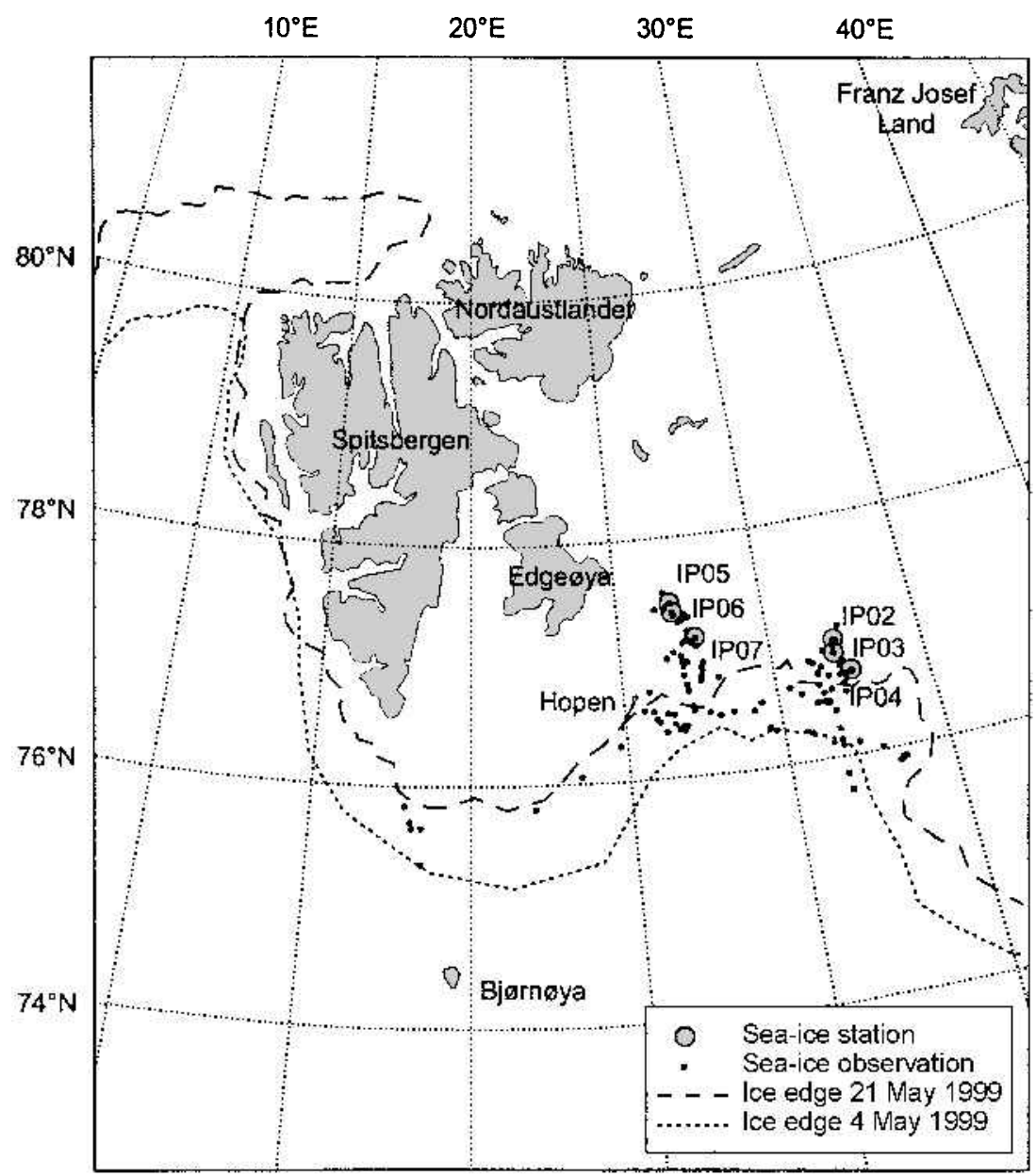

Fig. 1. Map showing the research area in the Barents Sea, east of Hopen. Positions of ice observations (visual ice description from the ship's bridge) are marked by black dots; ice stations with in situ measurements are marked by large grey circles with labels IP02IP07. The dotted and dashed lines indicate the ice-edge position at the beginning and end of the observation period, respectively.

is a universal function of the ratio $\zeta=z / L$, where $L$ is the Monin-Obukhov length scale:

$$
\begin{aligned}
L & =U_{*}^{2} / \kappa^{2} B T_{*} \\
U_{*} & =(\tau / \rho)^{1 / 2}, \\
T_{*} & =-H / \kappa \rho c_{\mathrm{p}} U_{*}, \\
B & =g / T_{z},
\end{aligned}
$$

where $z$ is measurement level, $U_{*}$ is dynamic velocity, $\kappa$ is the von Kármán constant, $B$ is the buoyancy parameter, $\tau$ is the frictional stress, $T_{*}$ is the temperature scale, $H$ is the vertical turbulent flux of sensible heat, $\rho$ is air density, $c_{\mathrm{p}}$ is specific heat of air, $g$ is gravitational acceleration and $T_{z}$ is air temperature at the level $z$. Proceeding from this, we obtain a system of equations defining the turbulent heat fluxes under the assumption that $T_{z}$ at the roughness length level $\left(z_{0}\right)$ is identical to the surface temperature $T_{\mathrm{S}}$ and that the wind velocity $U_{z}$ is zero (Makshtas, 1991):

$$
\begin{aligned}
U_{z}= & U_{*} / k\left[f(z / L)-f\left(z_{\mathrm{o}} / L\right)\right] \\
T_{z}-T_{s}= & T_{*}\left[f(z / L)-f\left(z_{\mathrm{o}} / L\right)\right] \\
& \ln (\zeta)+\beta \zeta \quad \text { when } \quad \zeta>0 \\
f(\zeta)= & \ln |\zeta| \quad \text { when } \quad-0.07<\zeta<0 \\
& 0.25+1.2 \zeta^{1 / 3} \quad \text { when } \quad \zeta<-0.07 .
\end{aligned}
$$

For known $U_{z}$ and $T_{z}$ at two levels (one of them open water or sea-ice surface), we can obtain a closed system of equations for calculating the parameters determining tur- bulent flow in the surface layer, $U_{*}, T_{*}$ and $L$. Then $H$ becomes:

$$
H=-\kappa \rho c_{\mathrm{p}} U_{*} T_{*} .
$$

The effect of air humidity on the density stratification of the atmosphere surface layer was taken into account by an addendum (Zilitinkevich, 1970):

$$
L_{*}=L\left(1+m / B_{\mathrm{o}}\right)^{-1},
$$

where $m$ is the non-dimensional coefficient and $B_{\mathrm{o}}$ is the Bowen ratio. Assuming that the process of turbulent exchange of heat and vapour in the surface layer are identical then $B_{0}$ can be defined as:

$$
B_{\mathrm{o}}=\frac{c_{\mathrm{p}}\left(T_{z}-T_{\mathrm{s}}\right)}{l\left(q_{z}-q_{\mathrm{s}}\right)},
$$

where $l$ is the specific heat of evaporation, and $q_{z}, q_{\mathrm{s}}$ are the specific humidity at level $z$ and at the water or sea-ice surface, respectively. The calculations of $q_{z}$ and $q_{\mathrm{s}}$ were made using the Magnus formula (Zilitinkevich, 1970) relating these quantities to water-vapour pressure:

$$
\begin{aligned}
q_{\mathrm{s}} & =0.622\left[e\left(T_{\mathrm{s}}\right) / P\right] f \\
q_{z} & =0.622\left[e\left(T_{z}\right) / P\right],
\end{aligned}
$$

where $e(T)$ is saturation vapour pressure, $P$ is atmospheric 
pressure and $f$ is relative humidity. $e(T)$ can be determined knowing $f, T_{\mathrm{S}}$ and $T_{z}$ :

$$
\begin{aligned}
& q_{\mathrm{s}}=0.622\left(e_{0} / P\right) 10^{\left[a_{1}\left(T_{\mathrm{s}}-273\right) /\left[b_{1}+\left(T_{\mathrm{s}}-273\right)\right]\right.} \\
& q_{z}=0.622\left(e_{0} f / P\right) 10^{\left[a_{1}\left(T_{z}-273\right) /\left[b_{1}+\left(T_{z}-273\right)\right]\right.},
\end{aligned}
$$

with $e_{0}=611 \mathrm{~Pa}, a_{1}=9.5$ and $b_{1}=265.5$. The two latter are empirical coefficients for ice (for water: $a_{1}=7.63$ and $b_{1}=$ 241.9). In Equation (13) it is assumed that the air at the surface is saturated by water vapour. Then, assuming that the profiles of $T_{z}$ and $q_{z}$ correlate, as experimentally and theoretically shown (Monin and Obukhov, 1954; Monin and Yaglom, 1975), we can express the latent turbulent heat flux LE in the atmospheric surface layer as follows:

$$
\mathrm{LE}=H / B_{\mathrm{o}} .
$$

Estimating a representative value for the aerodynamic roughness length of the sea-ice surface $\left(z_{0}\right.$, roughness parameter) is difficult and presents a problem for use of this algorithm. For this study, measurements were made at the surface, $z_{1}=z_{0}$ and thus the corresponding $U_{z}=0$. Experimental estimations of $z_{0}$ are available from a number of ground-truth measurements made from drifting sea ice in the Arctic basin (Doronin, 1971; Langleben, 1972; Holmgren and Weller, 1974; Wadhams, 1986; Andreas, 1987; Guest and Davidson, 1987, 1991; Makshtas, 1991). These researchers have also carried out studies showing how $z_{0}$ depends on parameters such as snow thickness, surface snow morphology, hummocks and ridge characteristics, as well as ice conditions.

In the Barents Sea MIZ we observed a complicated diversity of sea-ice types and ice concentrations within the study area. We made the following simplifications for the calculation of turbulent heat flux since we lacked surface roughness data for the complex ice situation in this nonhomogeneous environment: (1) that the roughness length for momentum and heat transfer is equal, and (2) that the roughness length is independent of the ice concentration. We selected values based on earlier studies, where $z_{\mathrm{o}}$ ranges from $10^{-4}$ to $10^{-3} \mathrm{~m}$ (Guest and Davidson, 1987, 1991). The calculated turbulent flux varies with varying roughness length (Fig. 2a). However, the corresponding total turbulent flux variation remained $<60 \%$.

\section{RESULTS}

The dominant ice types observed were even and rafted firstyear ice, as well as young ice and nilas. In situ measurements at ice stations showed that the thickness of undisturbed, level, first-year ice varied from approximately 0.5 to $1 \mathrm{~m}$. Multiyear ice was not observed. Ice floes classified as $3-10 \mathrm{~m}$ in diameter were most abundant, followed by the class $1-3 \mathrm{~m}$ diameter. The position of the ice edge changed significantly during the cruise (Fig. 1). The MIZ was crossed twice on two separate transects $\left(\right.$ at $\sim 27^{\circ}$ and $32^{\circ} \mathrm{E}$ ). Additional observations were obtained when sailing along the ice margin. The two transects across the MIZ explain the two phases with high ice concentration: 7-12 and 16-20 May 1999 (Fig. 3 ). When crossing the ice edge from open water to ice, the percentage of ice cover did not always increase gradually. Large leads, interrupted by belts of small ice floes, contributed to an ice situation that was more complex than the low-resolution regional ice charts were able to indicate.

The temporal distribution of the meteorological parameters (e.g. atmospheric pressure, wind direction and air temperature in the surface layer) and characteristics of energy
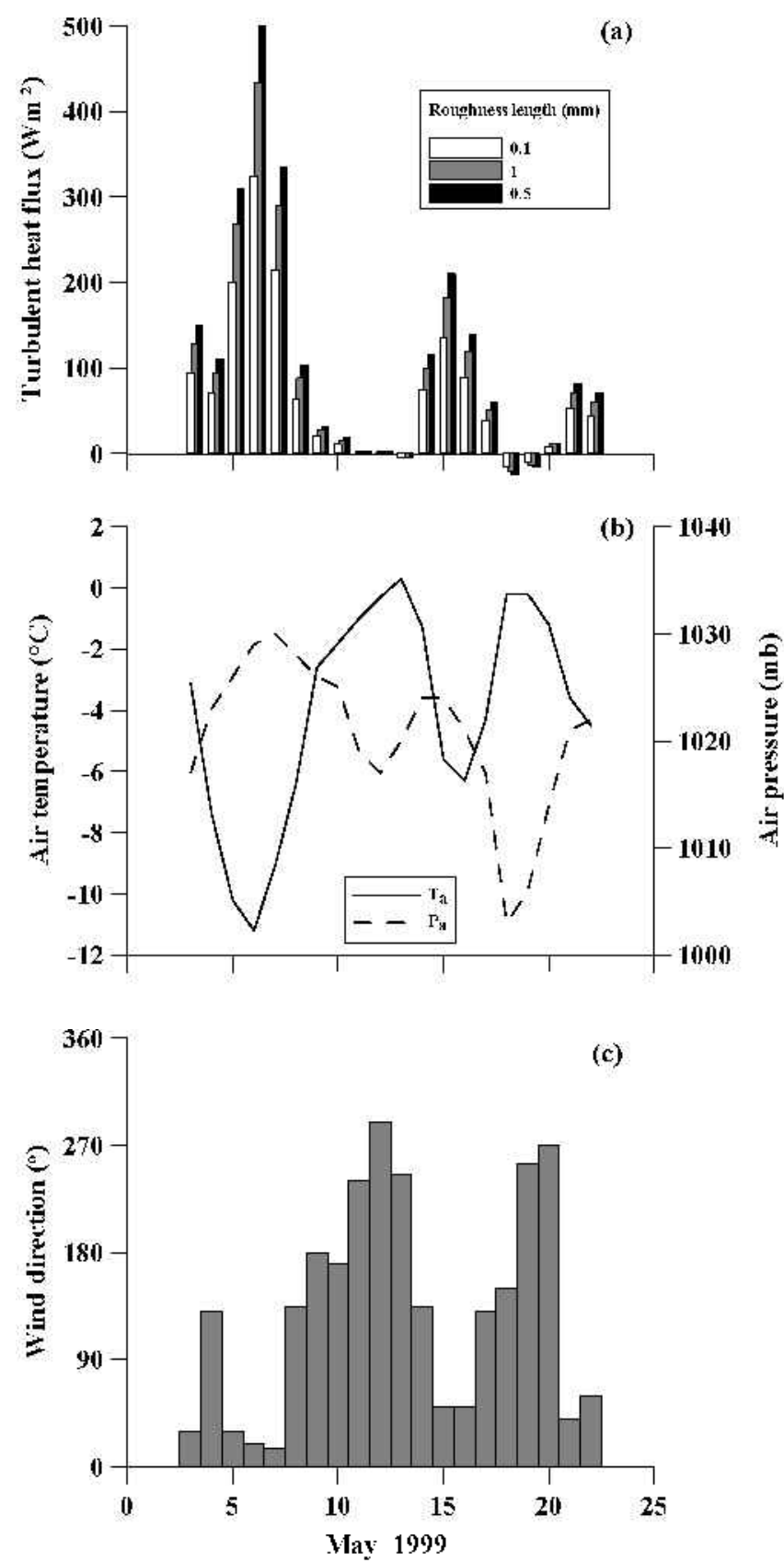

Fig. 2. (a) Time series of sensible and latent turbulent heat fluxes from open water in the Barents Sea MIZ during May 1999 (white bar: $Z_{0}=0.1 \mathrm{~mm}$; grey bar: $Z_{0}=0.5 \mathrm{~mm}$; black bar: $\left.Z_{0}=1 \mathrm{~mm}\right)$. (b,c) Time series of basic meteorological parameters in the Barents Sea MIZ during May 1999: air temperature and atmospheric pressure (b), and wind direction (c).

exchange in the MIZ shows a very close connection to the turbulent heat flux $H$ (Fig. $2 \mathrm{a}-\mathrm{c}$ ). Air temperature $\left(T_{\mathrm{a}}\right)$ and $H$ are dominantly anticorrelated, whereas atmospheric pressure $(P)$ and $H$ are correlated. Maxima in $H$ usually fall together with wind from the north and northeast (cold, ice-covered areas). These correlations are connected to the characteristic situation in the Barents Sea MIZ: high energy exchange, high atmospheric pressure and low surface air temperature are typical for anticyclonic situations and are connected to wind blowing from the ice-covered ocean towards open water (in general, wind directions varying between north and northeast; see Fig. 2c). On the other hand, low energy exchange, low pressure and relatively high air temperature are typical for cyclonic conditions (wind 


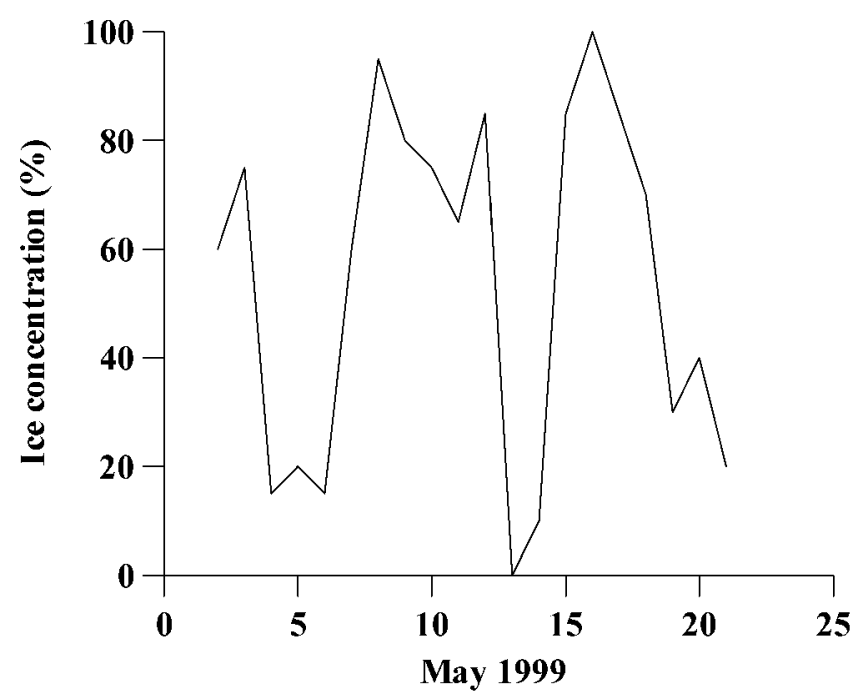

Fig. 3. Observed sea-ice concentration (in \%) in the Barents Sea MIZ during May 1999 (daily averages).

from open water towards ice-covered areas, i.e. wind directions between south and west; see Fig. 2). Accordingly, the turbulent heat flux distribution is closely related to the prevailing wind direction (Fig. $2 \mathrm{a}$ and c). The maximum turbulent fluxes were measured in the MIZ during anticyclonic situations. During an anticyclonic situation these relationships can be explained by significant differences between the air and surface temperatures (open water, young ice or very low concentrations of first-year ice). During periods of cyclonic weather, these differences are considerably lower, so the intensity of turbulent heat flux is also lower. As one would expect, we obtained maximum turbulent energy exchange values $\left(300-500 \mathrm{~W} \mathrm{~m}^{-2}\right)$ during periods of high wind speed from a northerly direction (Fig. 2c) (e.g. 5-8 May 1999; wind speed $>10 \mathrm{~m} \mathrm{~s}^{-1}$ ).

The surface temperature $\left(T_{\mathrm{S}}\right)$ was derived from outgoing longwave radiation measurements. This value can be considered as an integral (spatial average) temperature for the selected area of the sea surface. This area may include open water and varying types of sea ice (e.g. first-year ice). This instrument does not view directly downward but is angled from the vertical in order to obtain an average "integral" temperature over approximately $100 \times 100 \mathrm{~m}^{2}$ and to avoid interference from the ship's structure. The time series of $T_{\mathrm{a}}$, open-water temperature $\left(T_{\mathrm{w}}\right)$ and $T_{\mathrm{s}}$ are shown in Figure 4 . There are extended periods of time $\left(8^{-13}\right.$ and $18-$ 20 May 1999) when $T_{\mathrm{S}}$ was at least $2^{\circ} \mathrm{C}$ lower than $T_{\mathrm{a}}$. Usually this occurred in conditions with a high concentration of first-year ice and wind from the southwest. Under such conditions, the stratification of the surface layer is stable, causing such temperature contrasts in the lowest $12 \mathrm{~m}$ of the atmosphere.

We carried out an independent calculation of turbulent heat fluxes with the Monin-Obukhov similarity theory (Equations (1-14)) using the time series of $T_{\mathrm{S}}$, and obtained a good correlation between daily average integral turbulent heat fluxes (spatial average) and visual estimations of ice concentration for springtime in the MIZ (Fig. 5). The correlation coefficient for the logarithmic approximation is 0.7. In this context, "ice concentration" means all types of ice observed in the MIZ. The average concentration of thick first-year ice in the MIZ was approximately $40 \%$. The total concentration of young ice and nilas was $<10 \%$ during the period of our observations,

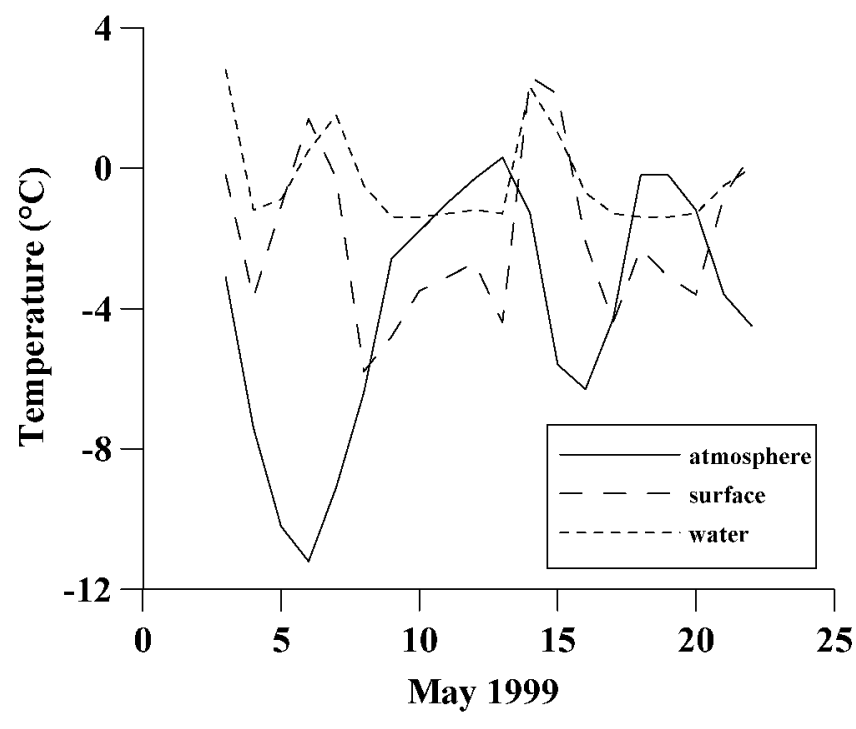

Fig. 4. Time series of air temperature (solid line, $T_{\mathrm{a}}$ : atmosphere), water temperature (short-dashed line, $T_{\mathrm{w}}$ : water) and integral surface temperature $T_{\mathrm{S}}$ (long-dashed line: surface), obtained by the ship's weather station and from the infrared radiometer.

i.e. a typical ice scenario consisted of $40 \%$ first-year ice, $10 \%$ young ice and $50 \%$ open water. This approach can be considered as a simple indirect method (e.g. when surface energybalance measurements are not available) for calculating turbulent fluxes in the MIZ during springtime.

Finally, we can calculate the total surface heat balance in the MIZ (monthly average estimations). The surface heat balance $B_{\mathrm{s}}$ equals:

$$
B_{\mathrm{s}}=Q_{\mathrm{s}}(1-A)\left(1-i_{\mathrm{o}}\right)+H+\mathrm{LE}+B_{\mathrm{g}},
$$

where $Q_{\mathrm{s}}$ is the incoming shortwave solar radiation, $A$ is the average surface albedo, $i_{\mathrm{o}}$ is the transmission coefficient characterizing the part of shortwave radiation passing through the surface $\left(i_{\mathrm{o}}=0\right.$ for snow cover and $i_{\mathrm{o}}=0.3$ for sea ice without snow; Semtner, 1976) and $B_{g}$ is surface longwave balance. Average estimations for $Q_{\mathrm{s}}, H, \mathrm{LE}$ and $B_{\mathrm{g}}$

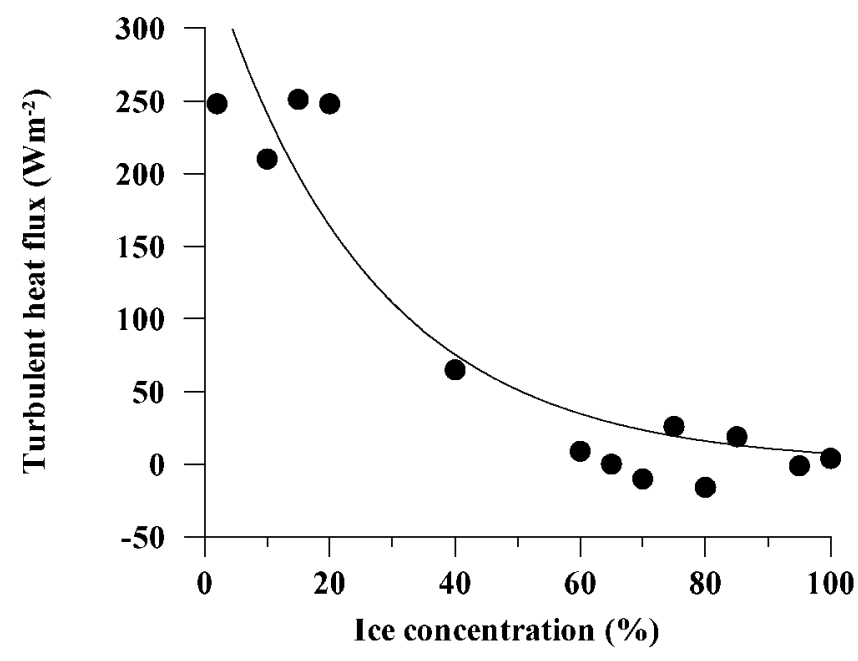

Fig. 5. Correlation between calculated turbulent heat fluxes and observed sea-ice concentration in the Barents Sea MIZ during May 1999 (dots: $H_{\mathrm{a}}\left(N_{\mathrm{o}}\right)$; line: logarithmic parameterization). 
Table 1. Surface heat balance in the Barents MIZ during May 1999. All units are $\mathrm{Wm}^{-2}$

$Q_{\mathrm{s}}(1-A)\left(1-i_{\mathrm{o}}\right) \quad H+\mathrm{LE} \quad B_{\mathrm{g}} \quad B_{\mathrm{s}} \quad$ Source

$\begin{array}{llll}+78 & +16 & +13 & \text { This study } \\ +54 & +34 & & \text { Nikolajev and others (1984) }\end{array}$

Notes: Negative values indicate downward heat flux, i.e. from the atmosphere to the sea surface; positive values indicate upward heat flux, i.e. from the surface to the atmosphere. $Q_{\mathrm{s}}$ is incoming shortwave radiation, $A$ is albedo, $H$ is sensible-heat flux, LE is latent heat flux, $B_{\mathrm{g}}$ is surface longwave balance and $B_{\mathrm{s}}$ is surface heat balance. Averaged data from Nikolajev and others (1984) refer to a study in the same area in 1983.

were calculated for the period 3-22 May 1999. As a first approach, we formulate the surface albedo $(A)$ as:

$$
A=\frac{A_{1} N_{1}+A_{2} N_{2}+A_{3} N_{3}}{100},
$$

where $A_{1}$ and $N_{1}$ are albedo and relative concentration of first-year ice, $A_{2}$ and $N_{2}$ are albedo and relative concentration of young ice (dark and light nilas, grey and grey-white) and $A_{3}$ and $N_{3}$ are albedo and relative area of open water. We used in situ measurements of the sea-ice albedo in the MIZ to obtain $A_{1}, N_{1}, A_{2}, N_{2}, A_{3}$ and $N_{3}$. Further, we used available ground-truth information (Ivanov, 1999) to determine the dependence of albedo on ice thickness (for first-year ice with and without a thin snow cover) and our visual observations of sea-ice conditions (fractional concentration of young ice and first-year ice). The contribution of first-year ice $\left(N_{1}\right)$ to the total sea-ice concentration was $40 \%$, the contribution of young ice $\left(N_{2}\right) 10 \%$, and the contribution of open water $\left(N_{3}\right)$ $50 \%$. Thus, with this situation, $A$ in the MIZ was about 0.4 . Accordingly, there are different contributions to the surface heat balance from radiation and turbulent components (see Table 1).

These results correspond reasonably well with earlier investigations, performed on board the Russian icebreaker Otto Schmidt in this part of the Barents Sea in May 1983 (Nikolajev and others, 1984), and theoretical work (Overland and others, 1983), reflecting the large interannual sea-ice variations in the Barents Sea (Vinje and Kvambekk, 1991). The absence of visible melting on the ice surface, and the presence of young ice at the sea surface further confirms our calculations and estimations (positive sum of heat flux from ocean to atmosphere). We can use these estimations of surface heat balance as lower boundary conditions for atmospheric boundary layer modelling and local climate models (Randall and others, 1998).

\section{GONGLUSIONS}

New data were obtained on atmospheric surface layer characteristics in the Barents Sea MIZ. This dataset was used to establish representative estimations of surface heat-balance components in the MIZ for springtime conditions. In situ infrared radiation measurements of sea-ice temperature were used to calculate the turbulent heat exchange using the Monin-Obukhov similarity theory. We found a relation- ship between turbulent heat fluxes (model calculation) and sea-ice concentration (visual observations).

\section{AGKNOWLEDGEMENTS}

We are grateful to the ship's crew of R/V Lance for support in carrying out this study. We also would like to thank V. Squire, M. Lange and two anonymous reviewers for their constructive comments that helped us to improve this paper. V. Churun (Arctic and Antarctic Research Institute, St Petersburg) helped us in the final stage with revisions of the figures. The Norwegian Polar Institute financially supported this study. The preparation of the manuscript was supported through the NATO Collaborative Linkage grant No. EST. CLG.975781.

\section{REFERENGES}

Andreas, E. L. 1987. A theory for the scalar roughness and the scalar transfer coefficients over snow and sea ice. Boundary-Layer Meteorol., 38(1-2), 159-184. Brown, R. A. 1986. The planetary boundary layer in the marginal ice zone. CRREL Spec. Rep. 86-3, MIZEX Bulletin 7, 65-78.

Doronin, Yu. P. 1971. Thermal interaction of the atmosphere and the hydrosphere in the Arctic. Philadelphia, PA, Coronet Books.

Guest, P. S. and K. L. Davidson. 1987. The effect of observed ice conditions on the drag coefficient in the summer East Greenland Sea marginal ice zone. 7. Geophys. Res., 92(C7), 6943-6954.

Guest, P. S. and K. L. Davidson. 1991. The aerodynamic roughness of different types of sea ice. 7. Geophys. Res., 96(C3), 4709-4721.

Holmgren, B. and G. Weller. 1974. Local radiation fluxes over open and freezing leads in the polar pack ice. AID JEX Bull. 27, 149-166.

Ivanov, B. V. 1999. New data on sea-ice albedo in the Laptev and Barents Seas. In Kassens, H. and 7 others, eds. Land-ocean systems in the Siberian Arctic: dynamics and history. Berlin, etc, Springer-Verlag, 59-63.

Ivanov, B.V. and A. P. Makshtas. 1988. Algoritm dlya rascheta turbulentnogo obmena $\mathrm{v}$ povermnostnom sloie atmosfery. [An algorithm for calculation of turbulent exchange in the atmosphere surface layer.] Fournal of Atmospheric Physics, Lithuanian Academy of Science, 11, 54-63.

Langleben, M. P. 1972. A study of the roughness parameters of sea ice from wind profiles. 7. Geophys. Res., 77(30), 5935-5944.

Makshtas, A. P. 1991. The heat budget of the Arctic ice in the winter. English edition. Cambridge, International Glaciological Society.

Monin, A. S. and A. M. Obukhov. 1954. Osnovniie zakonomernostiturbulentnogo peremeshivaniia $\mathrm{v}$ prizemnom sloie atmosfery. [Basic regularity in turbulent mixing in the surface layer of the atmosphere.] Trudy Instituta Geofiziki (Akademiia Nauk SSSR), 24, 163-187. (English translation NTIS AD-672723)

Monin, A. S. and A. M. Yaglom. 1975. Statistical fluid mechanics: mechanics of turbulence.Vol. 1. Cambridge, MA, MIT Press.

Nikolaev, Yu.V., A. P. Makshtas and B.V. Ivanov. 1984. Fizicheskiie processi v prikromochnikh zonah dreifuiuschih morskih ldov. [Physical processes in the marginal zone of drifting sea ice.] Meteorol. Gidrol., 1984(11), 73-80.

Overland, J. E., R. M. Reynolds and C. H. Pease. 1983. A model of the atmospheric boundary layer over the marginal ice zone. 7. Geophys. Res., 88(C5), 2836-2840.

Randall, D. and 9 others. 1998. Status of and outlook for large-scale modeling of atmosphere-ice-ocean interactions in the Arctic. Bull. Am. Meteorol. Soc., 79(2), 197-219.

Semtner, A. J., Jr. 1976. A model for the thermodynamic growth of sea ice in numerical investigations of climate. 7. Phys. Oceanogr., 6(5), 379-389.

Steffen, K. 1986. Atlas of the sea-ice types: deformation processes and openings in the ice. North Water Project. Zürcher Geogr. Schr. 20.

Vinje, T. and Å. S. Kvambekk. 1991. Barents Sea drift ice characteristics. Polar Res., 10(1), 59-68.

Wadhams, P. 1986. The seasonal ice zone. In Untersteiner, N., ed. Geophysics of sea ice. London, etc., Plenum Press, 825-991. (NATO ASI Series B: Physics 146.)

Zilitinkevich, S. S. 1970. Dinamica pogranichnogo sloia atmosferi. [Dynamic of boundary layer of atmosphere.] Leningrad, Gidrometeorologicheskoye Izdatel'stvo. 